\title{
Non-Adiabatic Dynamics Simulations of a Light-Driven Molecular Motor in Solution
}

\author{
Jin Wen, ${ }^{*, \dagger}$, Sebastian Mai,,+ and Leticia González ${ }^{*, \ddagger}$ \\ †State Key Laboratory for Modification of Chemical Fibers and Polymer Materials, College \\ of Materials Science and Engineering, Donghua University, Shanghai 201620, China \\ $\ddagger$ Institute of Theoretical Chemistry, Faculty of Chemistry, University of Vienna, \\ Währinger Str. 17, 1090 Vienna, Austria \\ E-mail: jinwen@dhu.edu.cn; leticia.gonzalez@univie.ac.at
}

\begin{abstract}
Despite molecular motors have numerous potential applications in optoelectronics, where optical properties can be tuned to transform light into mechanical movements, finding relationships between molecular motion and the environment is challenging. Here, we report the first excited state dynamics study of an overcrowded alkene in solution using a hybrid quantum mechanics/molecular mechanics (QM/MM) approach combined with non-adiabatic molecular dynamics simulations. Using QM/MM surfacehopping trajectories, we calculate time-resolved emission and transient absorption spectra. These show the rise of a short-lived Frank-Condon state in the first $150 \mathrm{fs}$, followed by a formation of a dark state, before the motor relaxes to the ground state in about 1 ps. From the analysis of radial distribution functions we infer that the orientation of the solvent in the electronic excited state is similar to that in the ground state during the photoisomerization.
\end{abstract}




\section{Introduction}

Artificial molecular machines are assemblies held together by van der Waals interactions that allow the conversion of chemical or light energy into mechanical work in accomplishing a useful task. ${ }^{1,2}$ Among them, synthetic molecular rotatory motors have attracted a lot of interest in the applications as biomolecular sensors, electronic devices, or photoswitchable catalysts. ${ }^{3,4}$ In a motor, mechanical work is achieved by a large amplitude motion, for instance a cis/trans isomerization. This is the case in the chiroptical overcrowded alkenes first developed by Feringa and coworkers in $1999^{5}$ and in the limelight since then. ${ }^{6-8}$ Chirality ensures unidirectional rotation around an axle consisting of a double $\mathrm{C}=\mathrm{C}$ bond, exploiting sequential four-step cycles where cis/trans photoisomerization alternates with thermal inversion.

While first-generation motors based on overcrowded alkenes had two identical halves connected by $\mathrm{C}=\mathrm{C}$ bond,${ }^{5}$ later developments included different rotator and stator parts -as in the example shown in Fig. 1- thereby achieving significant rotary speed gains. ${ }^{9}$ The efficiency of a molecular rotor is both limited by the quantum yield in the photoisomerization and the reaction barrier in the thermal inversion process. New generations pursue an increase in the rotational frequency of the motor up to the $\mathrm{MHz}$ scale. ${ }^{9-14}$ In this quest to achieve higher frequencies, a precise spatio-temporal control is best if the working rotary process is well understood and its collective behavior in solution or on attached surfaces ${ }^{15,16}$ can be predicted at molecular level.

The light-activated step of a molecular motor can be best monitored by time-resolved spectroscopy. ${ }^{17}$ It has been found that solution has a decisive role in obtaining high product yields. ${ }^{18}$ Viscosity of the medium affects dramatically the photochemical quantum yield for cis/trans isomerization - with high yields for high solvent viscosity and low yields for low viscosity; ${ }^{19}$ thus designing molecular motors in particular conditions of polarity and viscosity is still a challenge. ${ }^{20}$ In this endeavour, electronic structure calculations and dynamics simulations can help predicting the effect of a particular solvent on the rotary cycle, including 


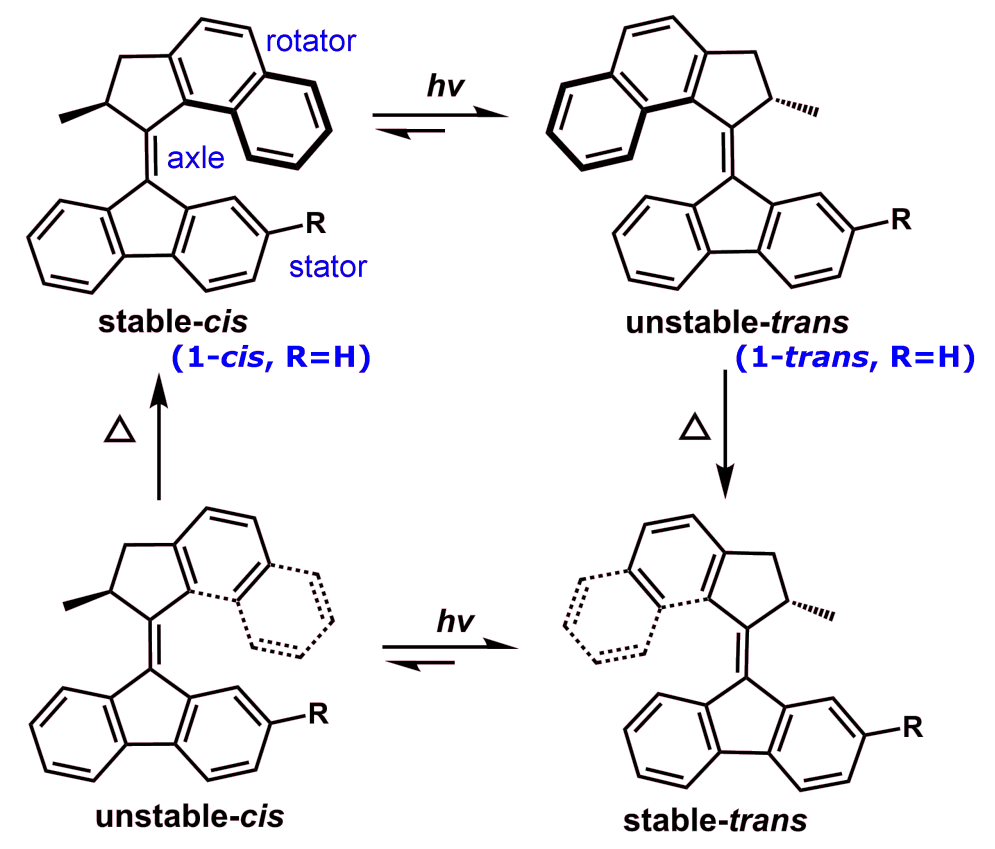

Figure 1: Schematic working process of the molecular motor.

the light-induced step. Yet, previous studies devoted to connect the ultrafast dynamics of molecular motors to time-resolved experiments have been restricted to calculations in gas phase. ${ }^{21-23}$

Thus, the aim of this paper is to investigate the role of solvents in the photoinduced rotational step of a molecular motor. To this purpose we use non-adiabatic dynamics simulations combined with a hybrid quantum mechanical/molecular mechanics (QM/MM) approach that allows to take explicit solvent molecules into account. As a molecular model we choose compound 1 (depicted in Fig. 1) in dimethyl sulfoxide (DMSO), which is a common solvent used in previous experimental studies due to its good solvation properties. ${ }^{24}$

\section{Computational Methods}

In order to investigate the cis/trans photoisomerization dynamics of $\mathbf{1}$, we employed nonadiabatic dynamics simulations based on surface hopping trajectories, as implemented in Surface Hopping including ARbitrary Couplings (SHARC) ${ }^{25,26}$ in the combination with an electrostatic quantum mechanical/molecular mechanics (QM/MM) embedding approach. As 
shown schematically in Figure 2, the QM part contained the molecular motor and solvent molecules were treated by the force field in the MM part .

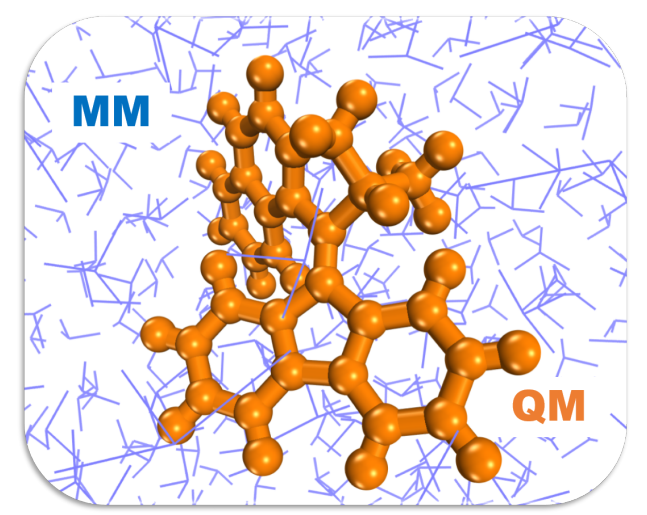

Figure 2: Schematic QM/MM model: molecular motor in the QM region (in orange), DMSO solvent in the MM region (in purple).

Our methodological procedure consisted of three steps, which would be described below. The first step was to choose a suitable QM theory in the calculations of the electronic structures. To this aim, we calculated the electronic excited states of $\mathbf{1}$ in gas phase with different methods to compare with the experimental results. ${ }^{9}$ As a second step, classical molecular dynamics (MD) simulations in the electronic ground state were carried out to generate an ensemble of adequate initial conditions that served for the posterior QM/MM calculations. Finally, trajectories in the electronic excited state were initialized by the method selected in the first step, then propagated in the QM/MM framework. The results would be compared with the experimental time-resolved signals. ${ }^{17,27}$ In the following, the computational details involved in the three steps would be addressed.

\subsection{Electronic structure calculations}

The geometries of stable-cis (denoted as 1-cis, $\mathrm{R}=\mathrm{H}$ ) and unstable-trans (1-trans) configurations were optimized at B3LYP/cc-pVDZ level and confirmed by subsequent frequency calculations. Electronic excited states were then calculated with the following methods: multistate complete-active-space second-order perturbation theory (MS-CASPT2), ${ }^{28}$ multi- 
configuration pair-density functional theory (MC-PDFT), ${ }^{29,30}$ the second order algebraicdiagrammatic scheme for the polarization operator $\mathrm{ADC}(2),{ }^{31}$ and time-dependent density functional theory (TD-DFT) ${ }^{32}$ with B3LYP functional. According to the benchmark work in Ref. 33, the IPEA shift was set as 0.0 a.u. in MS-CASPT2 calculations. Te same active space in a state-average complete-active-space self-consistent field (SA-CASSCF) calculations was employed in both MC-PDFT and MS-CASPT2 calculations. The tested active spaces ranged from $(4,4),(8,8)$ to $(12,12)$. It was found that the MC-PDFT method based on tBLYP functional ${ }^{34}$ was able to reduce the computational cost in the comparison with MS-CASPT2 method without losing accuracy. After checking the electronic transitions, we included 2-4 states to guarantee that the bright state was included. In all cases the cc-pVDZ basis set ${ }^{35}$ was used.

$\mathrm{ADC}(2)$ was further employed to calculate relaxed potential energy surfaces of $\mathrm{S}_{0}$ (ground) and $\mathrm{S}_{1}$ (first excited) states along the rotational $\mathrm{C}=\mathrm{C}$ axle, based on B3LYP optimized geometries except for the constrained torsion angles. Furthermore, $\mathrm{ADC}(2)$ was used to obtain an absorption spectrum of 1-cis from 200 initial configurations, which would be described in the next subsection.

The MS-CASPT2 and MC-PDFT computations were done with OpenMolcas, ${ }^{36}$ the ADC(2) calculations were performed with TURBOMOLE 7.1, ${ }^{37}$ and the Gaussian 16 (Version A.03) software package ${ }^{38}$ was used in DFT and TD-DFT calculations.

\subsection{Classical molecular dynamics simulations}

Classical MD simulations for the full system (motor plus solvent) were employed to generate initial conditions where to subsequently propagate SHARC trajectories within a QM/MM framework.

In the MD simulations, the general AMBER force field (GAFF) ${ }^{39}$ was used for the molecular motor, which was solvated by 1434 DMSO molecules in a $12 \AA$ truncated octahedron box. Since the parameters of the solvent DMSO was not included in GAFF, the solvent box 
was parameterized according to Ref. 40. An NVT ensemble was propagated for 100 ps to heat the system to $300 \mathrm{~K}$ with a time step of $0.5 \mathrm{fs}$ without the SHAKE algorithm after minimization. The solvated box was equilibrated to 1 bar for $1 \mathrm{~ns}$ in an NPT ensemble, followed by the production in the NPT ensemble for 10 ns. A total of 200 geometry/velocity snapshots were extracted from this $10 \mathrm{~ns}$ production simulations at intervals of 50 ps to generate 200 initial conditions for the non-adiabatic dynamics simulations, described in the next subsection. The MD simulations were performed in the AMBER18 suite. ${ }^{41}$

In order to quantify solute-solvent interactions, radial distribution functions (RDFs) were evaluated for atom pairs along the trajectories. RDFs, $g(r)$, allowed to evaluate pair-wise interactions between two types of atoms of the solvents ( $\mathrm{S}$ and $\mathrm{O}$ atoms) around the solute. They were calculated as,

$$
g(r)=\frac{n(r)}{\rho 4 \pi r^{2} \Delta r},
$$

where $n(r)$ was the average number of solvent molecules in a spherical shell between radii of $r$ and $r+\Delta r$, and $\rho$ was the particle density. The $g(r)$ of the distances between $\mathrm{C}$ (motor)-S(DMSO) (noted as $\left.g_{\mathrm{C}-\mathrm{S}}\right), \mathrm{C}$ (motor)-O(DMSO) $\left(g_{\mathrm{C}-\mathrm{O}}\right), \mathrm{H}$ (motor)-S(DMSO) $\left(g_{\mathrm{H}-\mathrm{S}}\right)$, and $\mathrm{H}$ (motor)-O(DMSO) $\left(g_{\mathrm{H}-\mathrm{O}}\right)$ were analyzed with the AmberTools ${ }^{41}$ during the 10 ns dy-

namics with a bin size of $\Delta r=0.3 \AA$ in the MD simulations in the ground state. Correlations between two types of RDFs, $g_{\mathrm{C}-\mathrm{S}}$ and $g_{\mathrm{C}-\mathrm{O}}$, as varies of the distances $\mathrm{r}_{\mathrm{C}-\mathrm{S}}$ and $\mathrm{r}_{\mathrm{C}-\mathrm{O}}$ were further analyzed, which were presented as projections of them onto the planes composed by $\mathrm{r}_{\mathrm{C}-\mathrm{S}}$ and $\mathrm{r}_{\mathrm{C}-\mathrm{O}}$. The RDF correlations in the ground and excited states were analyzed by an in-house code. Combined with one and two dimensionally radial distributions, the orientation of solvent could be deduced.

\subsection{QM/MM excited-state dynamics}

According to the experimental excitation wavelength ${ }^{5}$ of $400 \mathrm{~nm}(3.10 \mathrm{eV})$ and the $\mathrm{ADC}(2)$ simulated absorption spectrum, only two singlet states $\left(\mathrm{S}_{0}\right.$ and $\left.\mathrm{S}_{1}\right)$ were deemed in need of 
the non-adiabatic dynamics simulations.

The ADC(2) method was used to generate energies and gradients in the QM/MM-SHARC simulations. Approximate non-adiabatic couplings were obtained from wave function overlaps computed by WFoverlap code. ${ }^{42}$ From the $\mathrm{ADC}(2)$ excitations corresponding to the total 200 initial conditions generated before, 133 snapshots were found from the bright state. From them, the first 23 were selected to run SHARC dynamics with a nuclear time step of 0.5 fs during 1 ps. After analyzing all these 23 trajectories, 5 trajectories showed cis/transisomerization within 1 ps and were further extended up to 2 ps to check their evolution on the excited state potential energy surface.

The local diabatization algorithm was used in the wave-function propagation. ${ }^{43}$ The energy-based decoherence correction ${ }^{44}$ was applied to counter the overcoherence problem. During surface hops, the full velocity vector was rescaled to adjust kinetic energy. The QM/MM-SHARC dynamics were carried out using the SHARC-RICC2 interface with TIN$\mathrm{KER}^{45}$ and TURBOMOLE ${ }^{37}$ in SHARC 2.1. ${ }^{25,26,46}$

To further get insight into the evolution of the trajectories, we optimized the minimum energy geometry in the $\mathrm{S}_{1}$ state and the conical intersection (CI) between $\mathrm{S}_{1}$ and $\mathrm{S}_{0}$ states at the $\mathrm{ADC}(2) / \mathrm{cc}-\mathrm{pVDZ}$ level using an external $\mathrm{ORCA}^{47}$ optimizer within SHARC. The default values ( $\sigma=3.5$ and $\alpha=0.02)$ were used in the optimization of a penalty function to obtain the minimal energy of CI. ${ }^{28}$

Transient absorption spectra within 1 ps were simulated based on the 23 trajectories with one excited-state collected at every 25 fs from the QM/MM-SHARC dynamics simulations. To simulate of the transient absorption spectra, the first 20 excitation energies in these geometries were calculated by $\mathrm{ADC}(2) / \mathrm{cc}-\mathrm{pVDZ}$ calculations, then convoluted with a Gaussian line shape of full width at half maximum (FWHM) of $0.3 \mathrm{eV}$. 


\section{Results and Discussion}

\subsection{Excitation energies and absorption spectrum in gas phase}

Describing the isomerization around the $\mathrm{C}=\mathrm{C}$ bond is challenging due to the biradical charac-

ter of the twisted geometry. As in other simpler alkenes, ${ }^{48-50}$ a twisted geometry corresponds to a $\mathrm{S}_{1} / \mathrm{S}_{0} \mathrm{CI}$. Given the multiconfigurational character of such structures, a multireference method is the preferred choice. However, including a sufficiently large amount of $\pi$ and $\pi^{*}$ orbitals in the active space makes excited state dynamics of such large systems unfeasible. In contrast, a single reference method, such as $\mathrm{ADC}(2)$ or TD-DFT, is computational efficient but has difficulties to describe the $\mathrm{S}_{1} / \mathrm{S}_{0}$ passage to the electronic ground state. With such a dilemma in mind, we first set to assess the performance of different methods in the calculation of the excited states of 1-cis and 1-trans configurations in the gas phase with optimized structures listed in Tables S1-S2 of the Supporting Information.

The vertical excitation energies of the bright $\left(\pi-\pi^{*}\right)$ state calculated by different methods are listed in Table 1 to compare with the experimental absorption band maximum in hexane. ${ }^{9}$ MS-CASPT2 and MC-PDFT excitation energies of all calculated states with active spaces from $(4,4)$ to $(12,12)$ are presented in Table S3 and Figures S1-S2.

Table 1: Vertical excitation energies ( $E$, in $\mathrm{eV}$ ) and oscillator strengths (f, in a.u.) of the $\pi-\pi^{*}$ excited state calculated by different methods with the cc-pVDZ basis set.

\begin{tabular}{lcc}
\hline Methods & 1-cis & 1-trans \\
\hline TD-B3LYP & $3.07(\mathrm{f}=0.45)$ & $2.78(\mathrm{f}=0.42)$ \\
ADC $(2)$ & $3.48(\mathrm{f}=0.13)$ & $3.12(\mathrm{f}=0.12)$ \\
MS-CASPT2 $^{a}$ & $2.74(\mathrm{f}=1.11)$ & $3.78(\mathrm{f}=0.58)$ \\
MC-PDFT $^{b}$ & $4.52(\mathrm{f}=0.09)$ & $4.79(\mathrm{f}=0.51)$ \\
Exp. $^{c}$ & 3.26 & 2.95 \\
\hline on SA-CASSCF $(12,12)$ & wavefunctions. ${ }^{b}$ based on SA-CASSCF $(12,12)$ and the \\
& tBLYP functional. & ${ }^{c}$ taken from Ref. 9
\end{tabular}

The deviation between single reference methods (TD-B3LYP and ADC(2)) and the experimental absorption maximum ranges from $0.1-0.2 \mathrm{eV}$ for both 1-cis and 1-trans species. The full $\pi$ and $\pi^{*}$ active space would correspond to $(24,24)$, which is not feasible in current 
MS-CASPT2 and MC-PDFT calculations. Therefore, smaller active spaces up to $(12,12)$ are tried, as shown in Table S3. The results show that the vertical excitation energies of both configurations, 1-cis and 1-trans, are overestimated by MC-PDFT calculations with active spaces from $(4,4)$ to $(12,12)$. Likewise, MS-CASPT2 using the same SA-CASSCF $(12,12)$ wave function gives errors of $0.5-0.8 \mathrm{eV}$ due to the small size of the active space. Accordingly, $\mathrm{ADC}(2)$ is taken as the selected method to calculate the absorption spectrum.

Fig. 3 shows the result obtained from $\operatorname{ADC}(2)$ calculations of the first and second excitations on a nuclear ensemble generated by initial conditions from the classical MD simulations. The simulated absorption spectrum gives a first transition at $3.35 \mathrm{eV}$ (about $370 \mathrm{~nm}$ ), which agrees reasonably with the first absorption band in hexane indicated by the blue line.

For completeness, we note here that the electronic character of this transition is an excitation from delocalized $\pi$ and $\pi^{*}$ orbitals with the largest contribution at the central $\mathrm{C}=\mathrm{C}$ bond, see Fig. S3A.

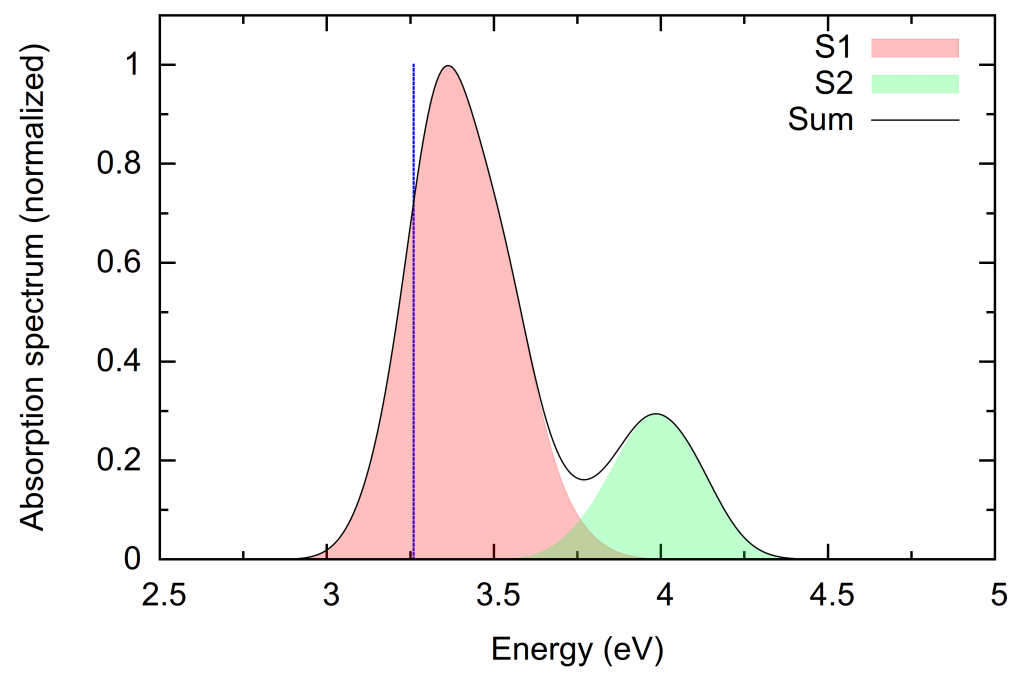

Figure 3: Simulated absorption of 1-cis by $\operatorname{ADC}(2) / c c-p V D Z$ calculations including only two excited states (Gaussian FWHM=0.2 eV, 200 initial conditions). The first peak in the experimental ${ }^{9}$ spectrum is presented in the blue line.

Further, we use $\operatorname{ADC}(2)$ to calculate relaxed $S_{0}$ and $S_{1}$ potential energy curves along the $\mathrm{C}=\mathrm{C}$ dihedral angles (Fig. S3B). The photoisomerization process could be further analyzed from the optimized structures along the reaction path, in particular by comparing minimum 
and $\mathrm{CI}$ geometries. The $\mathrm{C}=\mathrm{C}$ bond length is stretched from $1.37 \AA$ in the ground state to $1.46 \AA$ in the $\mathrm{S}_{1}$ minimum state. In the $\mathrm{ADC}(2)$ optimized $\mathrm{S}_{1}$ minimum and CI structures (Figure $\mathrm{S} 4$ ), the $\mathrm{C}=\mathrm{C}$ torsion angles are $-91.20^{\circ}$ and $-80.0^{\circ}$, respectively. In passing we note that according to the isomerization path in Fig. S3B, where the CI was optimized with DFT, the torsion angle is $-60^{\circ}$ at the CI, different from the $\mathrm{ADC}(2)$ optimized geometry (Fig. S4) by $20^{\circ}$.

In Ref. 17, the torsion angles of minimum in $\mathrm{S}_{1}$ state and CI structures are $100^{\circ}$ and $135^{\circ}$ from the potential energy surface, demonstrating that they are in twisted configurations. However, our $\mathrm{ADC}(2)$ optimized $\mathrm{S}_{1}$ minimum has a torsional angle of $-90^{\circ}$ and the CI of $-80^{\circ}$. Note that the definition of the torsional angles in Ref. ${ }^{17}$ is different, thus the sign of the angles are opposite to our $\mathrm{ADC}(2)$ optimized geometries. In the OM2/MRCI optimization in the gas phase by Pang and coworkers, ${ }^{23}$ the CI and $\mathrm{S}_{1}$ have similar torsion angles, $-110^{\circ}$ and $-100^{\circ}$ respectively, but different pyramidalization angles, -30 and $0^{\circ}$ respectively.

In summary, one can see that the $\mathrm{S}_{1}$ minimum is similar across the different methods available but differences in CI structure are more prominent due to the difficulty of several methods to describe biradical properties. In particular, a single reference method like $\mathrm{ADC}(2)$ cannot obtain an accurate $\mathrm{CI}$ geometry along the $\mathrm{C}=\mathrm{C}$ isomerization but still provides comparable $\mathrm{S}_{1}$ minimum geometries, when compared with the previous work. ${ }^{17,23}$ Accordingly, we conclude that $\mathrm{ADC}(2)$ seems to be a reasonable compromise to describe the ground and excited state potential energy surfaces, thus will be used as a compromise between computational cost and accuracy for dynamics calculations.

\subsection{Photoisomerization dynamics in solution}

The classical MD and QM/MM-SHARC simulations are performed to simulate the dynamics of motor in DMSO in the ground and excited states, respectively. Figure 4 shows the timeevolution of the $\mathrm{C}=\mathrm{C}$ torsion angles in the electronic ground state for 1-cis and 1-trans, as well as the $\mathrm{C}=\mathrm{C}$ bond lengths and the pyramidalization angles obtained from the classical 


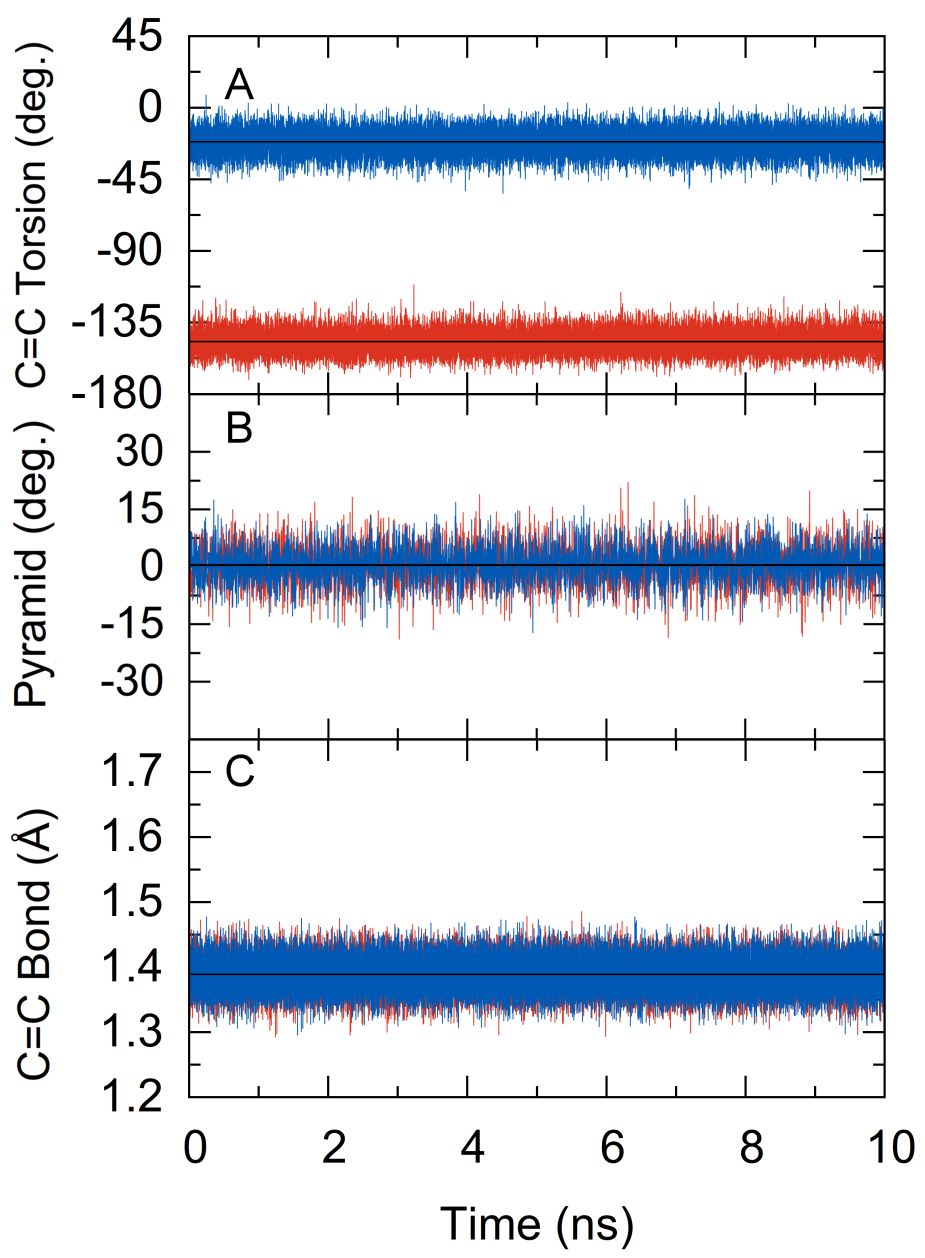

Figure 4: Ground state evolution of $(\mathrm{A}) \mathrm{C}=\mathrm{C}$ torsion, (B) pyramidalization, and $(\mathrm{C}) \mathrm{C}=\mathrm{C}$ bond length in 1-cis (blue) and 1-trans (red) during $10 \mathrm{~ns}$. Average values are depicted as black solid lines. 
MD simulations. The constant values demonstrate that both cis- and trans-configurations keep their original structures and the stator retains its planar conformation in the presence of the high viscous solvent DMSO during 10 ns of dynamics in the ground state.

The cis/trans-isomerization occurs upon electronic excitation to the $\mathrm{S}_{1}$ state, as demonstrated in the SHARC simulations in Figure 5. Density plots of the temporal evolution of the $\mathrm{C}=\mathrm{C}$ torsion, pyramidalization, and $\mathrm{C}=\mathrm{C}$ bond length are depicted in panels $\mathrm{A}-\mathrm{C}$ during 1 ps for 23 trajectories, and up to $2 \mathrm{ps}$ in panels $\mathrm{D}-\mathrm{F}$ for the fast 5 trajectories. The $\mathrm{C}=\mathrm{C}$ torsional angles stay around $-20^{\circ}$ (cis) in the $\mathrm{S}_{1}$ state during the first 400 fs and then change to $-90^{\circ}$ (twisted) in half of the trajectories (Fig. 5A), while the other half stay in the cisconfiguration. Isomerization to the trans-configuration is observed only in few trajectories, which are extended up to 2 ps (Fig. 5D). The pyramidalization (Fig. 5B and 5E) oscillates between $-15^{\circ}$ to $30^{\circ}$ meaning that the stator bends in the excited state. The $\mathrm{C}=\mathrm{C}$ bond length (Fig. $5 \mathrm{C}$ and $5 \mathrm{~F}$ ) quickly stretches from $1.35 \AA$ to $1.60 \AA$ because it changes from a formal $\mathrm{C}=\mathrm{C}$ double bond to a $\mathrm{C}-\mathrm{C}$ single bond in the excited state within the first $500 \mathrm{fs}$, then it oscillates within 1.40-1.50 $\AA$ at longer times. The evolution of $\mathrm{C}=\mathrm{C}$ torsion indicates that the fast isomerization occurs during the first $400 \mathrm{fs}$, which is in a good agreement with the observation of the stretching of the $\mathrm{C}=\mathrm{C}$ bond in the first $500 \mathrm{fs}$.

From the initial set of trajectories, 11 (48\%) change from cis to twisted configurations within 800 fs and 9 (39\%) stay in cis-configuration during 1 ps. The remaining 3 trajectories are the only ones that fully convert from cis to trans-configuration within $1.5 \mathrm{ps}$, amounting to $13 \%$ quantum yield in DMSO. This quantum yield is probably a lower bound due to the small number of trajectories and the short simulation time, but nevertheless consistent with that of $14 \%$ observed in dichloromethane (DCM) by the ultrafast spectroscopy. ${ }^{17}$

As stated above, the viscosity of the solvent affects the photodynamics of molecular motors. ${ }^{17,27,51}$ In the solvents with low viscosity, such as DCM and cyclohexane, it has been found that the reorientation did not affect the stability of the excited-state in the molecular motor, since identical kinetics have been observed in such solvents. ${ }^{17,27}$ In contrast, increasing 


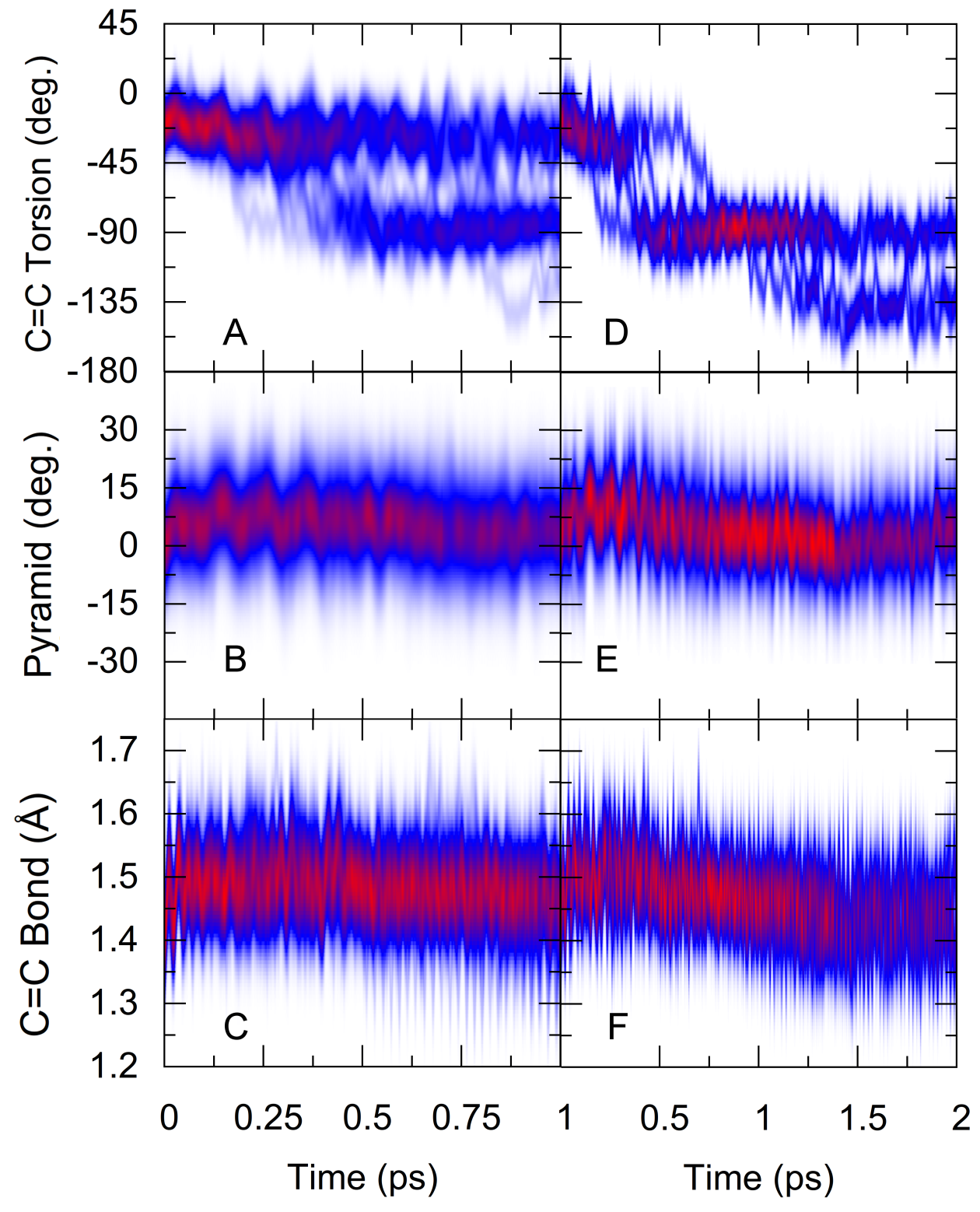

Figure 5: Time-resolved evolution of $\mathrm{C}=\mathrm{C}$ torsion, pyramidalization, and bond length in the $\mathrm{S}_{1}$ state, convoluted with a $20^{\circ}$ Gaussian for $1 \mathrm{ps}$ (panels A, B and C) in 23 trajectories, and 2 ps (panels D, E and F) in the fastest 5 trajectories. 
viscosity influences the equilibrium between stable and unstable configurations of a similar motor in a medium viscous solvent. ${ }^{51}$ Furthermore, according to Ref. 51, in a high viscous solvent DMSO, 1-trans configuration is expected to have a higher quantum yield than that in the lower viscous solvent. This would mean that the quantum yield from our simulation should be indeed underestimated. Unfortunately, it is not possible to increase the number of trajectories to obtain a more quantitative quantum yield due to the computational expense in our simulations.

As we anticipate, the twisted geometries involved in the cis/trans photoisomerization cannot be well described by a single reference approach like $\mathrm{ADC}(2)$ method, and this is reflected in our dynamical simulations. We use different representations $(\mathrm{R})$ to fit the populations of $\mathrm{S}_{0}$ and $\mathrm{S}_{1}$ states from the SHARC dynamics. In a character-based representation (denoted as $\mathrm{R} 1$ in Figure $6 \mathrm{~A}$ ), the single reference method $\mathrm{ADC}(2)$ always describes the ground state and excited state by a closed-shell wave function and an open-shell wave function, respectively. The hopping probability in this representation is so small that $\tau_{\mathrm{R} 1}$ (the life time of the open-shell wave function) is largely overestimated. In an energy-based representation ( $\mathrm{R} 2$ in Figure $6 \mathrm{~B})$, the $\mathrm{ADC}(2)$ excitation energy becomes negative at some geometries, therefore the open-shell state is lower in energy than the closed-shell state. In R2, we count whether the active state is located at the upper or lower energy surface. However, in this representation the back hop could occur whenever the excitation energy is negative again, resulting in an open-shell $\mathrm{S}_{1}$ state as the active state. When using single-reference methods in surface hopping, ${ }^{52}$ often a hop to the ground state is enforced manually when the energy gap is below a certain threshold. If we use such a hop criteria - e.g. hopping when the energy gap is smaller than $0.1 \mathrm{eV}$ - the active state is forced to stay in the closed-shell wave function (ground state) after the first hop. Without hopping backwards, the excited state $\mathrm{S}_{1}$ in this forced hop representation (denoted as R3 in Figure 6C) should decay faster than that in the $\mathrm{R} 2$ representation.

Unfortunately, these three different representations correspond to different kinetics, which 


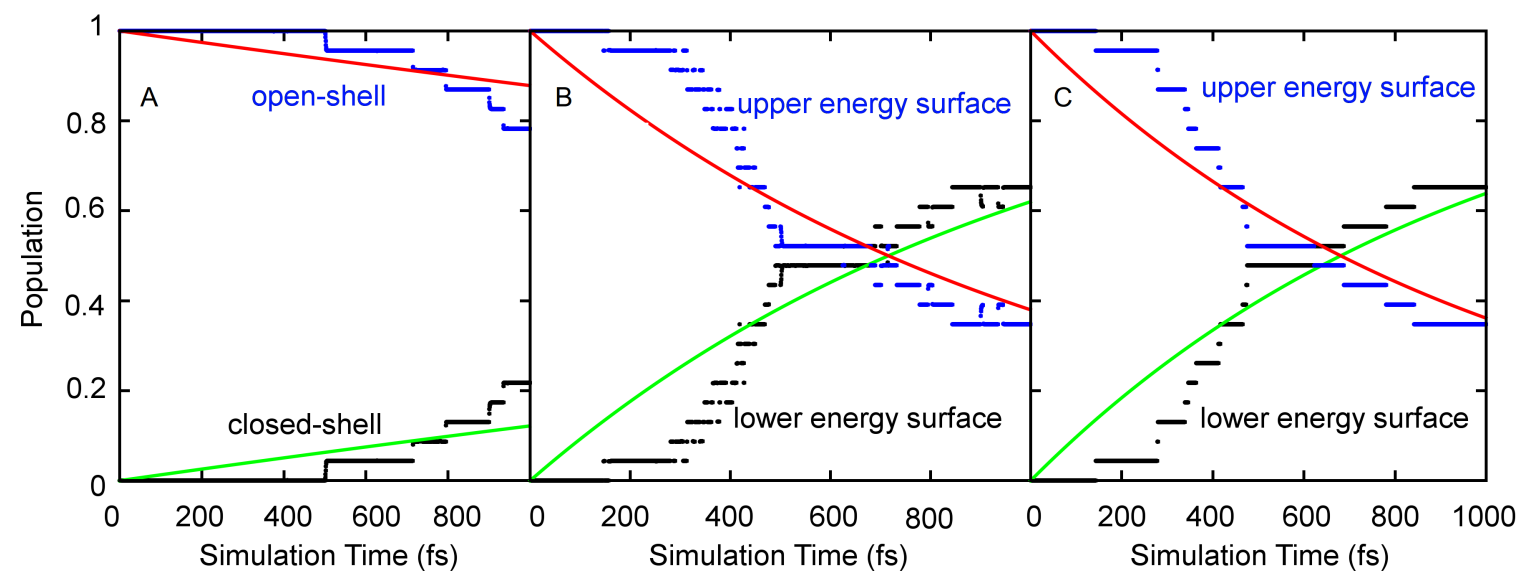

Figure 6: Time-evolution of the $\mathrm{S}_{1}$ and $\mathrm{S}_{0}$ populations in $(\mathrm{A})$ character-based (R1 representation), (B) energy-based (R2 representation), and (C) energy based enforcing a hop for energy gaps below $0.1 \mathrm{eV}$ (R3 representation).

makes interpretation of the dynamics cumbersome. The hopping probability in the R1 representation is underestimated, so the time constant is overestimated as high as $\tau_{\mathrm{R} 1}=$ $7710 \pm 75$ fs. As one can see in Figure $6 \mathrm{~A}$, the population of $\mathrm{S}_{1}$ state reduces slowly to $80 \%$ within 1 ps. In contrast, $\mathrm{S}_{1}$ decays much faster in the energy-based R2 and R3 representations, where only ca $35 \%$ remains in $\mathrm{S}_{1}$ after 1 ps. Accordingly, the time constants for the $\mathrm{S}_{1} \rightarrow \mathrm{S}_{0}$ reaction from the kinetic model are $\tau_{\mathrm{R} 2}=1033 \pm 5$ fs and $\tau_{\mathrm{R} 3}=982 \pm 5$ fs for R2 and R3 representations, respectively. The difference is related to the fact that back-hops are ignored in the $\mathrm{R} 3$ representation. In both cases (Figures $6 \mathrm{~B}$ and $6 \mathrm{C}$ ), the $\mathrm{S}_{1}$ population keeps as high as $48 \%$ during 500-700 fs, then about $40 \%$ population decays to the ground state within 1 ps. According to the analysis in the geometry evolution during 500-700 fs in Fig. 5A and 5B, about 50\% trajectories are trapped in the twisted configuration. Combined with $\mathrm{ADC}(2)$ optimized structure in $\mathrm{S}_{1}$ minimum (Fig. S4), we assign the trapped $48 \%$ population as the minimum in the $\mathrm{S}_{1}$ state during 500-700 fs. Only $13 \%$ of the population could reach the ground state of 1-trans configuration in 2 ps through the CI according to the population analysis in Fig. 5D.

In order to further inspect the isomerization, we prolonged the dynamics to 2 ps in the ground state for 12 trajectories, in which the $\mathrm{S}_{0} / \mathrm{S}_{1}$ energy gap is less than $0.1 \mathrm{eV}$. This is 
similar to enforce a hop to the ground state in selected trajectories which fulfil the energy requirement. If these trajectories could end in trans-configuration, the quantum yield is expected to be higher than the simulated $13 \%$. The evolution of the torsion parameters of the motor is presented in Figure S5. Unfortunately, all trajectories switch from twisted back to cis-configuration due to their failure in overcoming the barrier in the ground state.

In summary, evolution of the torsion within 2 ps demonstrates that reaching CI region is important to ensure the isomerization, otherwise the molecular motor could be trapped in the region of $\mathrm{S}_{1}$ minimum.

\subsection{Emission and transient absorption spectra}

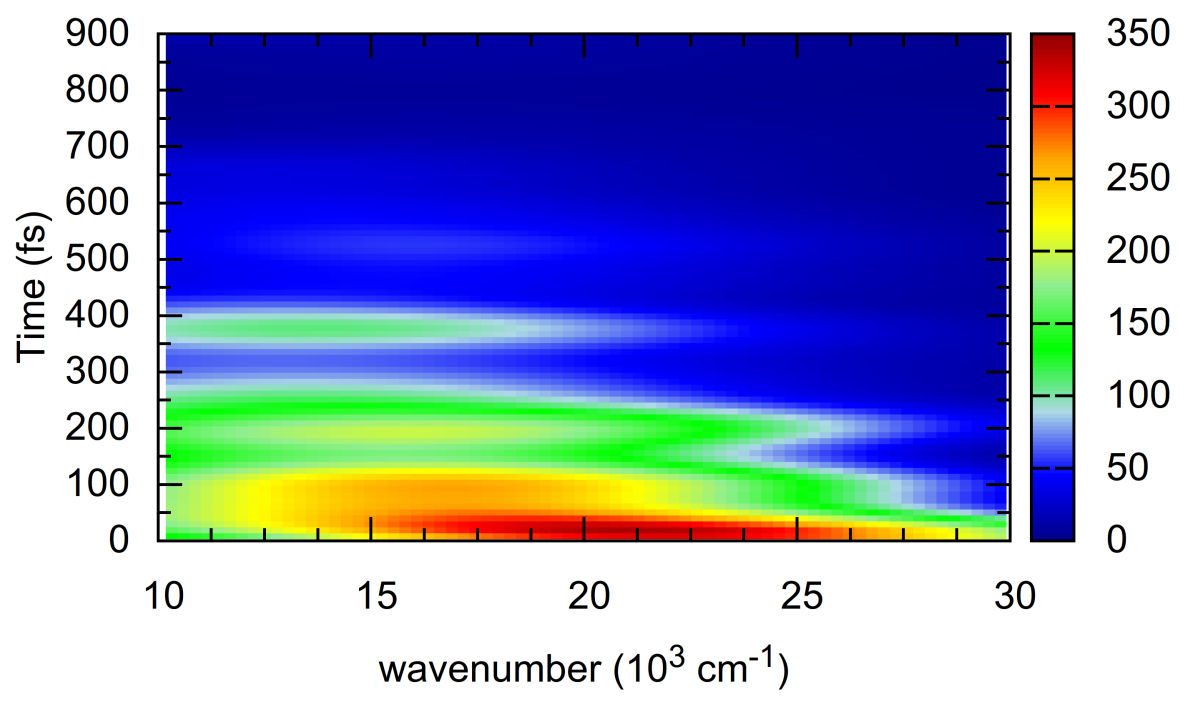

Figure 7: Simulated emission spectrum, convoluted with a $2.0 \mathrm{eV} \times 50$ fs Gaussian.

Fluorescence up-conversion experiments have been employed to investigate the initial motion of this motor. ${ }^{17}$ In particular, the intensity of emission spectra can be correlated to the lifetime of excited states. Based on the experimental spectrum, it has been suggested that a dark state with a low fluorescence-transition moment is generated within 100 fs from a fast structural evolution in the bright Franck-Condon state along the $\mathrm{S}_{1}$ potential surface; 
then the dark state undergoes slow radiationless decay to the ground state in about 1.5 ps. ${ }^{17}$ According to the emission signal, a direct conversion from the $\mathrm{S}_{1}$ state to the ground state through a CI by fast internal conversion is unlikely.

To investigate these hypothesis, we simulate the time-resolved emission spectrum including solvent from our QM/MM-SHARC trajectories, see Figure 7. There one can see that there is a fast quenching within the first 200 fs that completely vanishes after 700 fs. The emission intensity quickly decreases within the first 150 fs accompanied with a concomitant shift of the emission peaks from 21,000 to $17,000 \mathrm{~cm}^{-1}$ (see Figure S6). This red-shift of ca $4,000 \mathrm{~cm}^{-1}$ is also observed in the experimental emission spectrum within $150 \mathrm{fs}^{17}$ There, also a fast quenching with large red-shift was predicted in a reverse trans-cis isomerization process. The red-shift should occur in both cis-trans and trans-cis isomerizations, as has been confirmed by both theoretical predictions ${ }^{23}$ and experimental measurements. ${ }^{17}$ We note an oscillation at 16,000 and $15,000 \mathrm{~cm}^{-1}$ during $150-200 \mathrm{fs}$ and $350-400$ fs as yellow and green contours in Figure 7, respectively, which is consistent with the time-resolved deconvoluted emission. ${ }^{17}$ The oscillation strength of the emission spectra is stronger at the maximum in emission due to the coupling between the vibrational modes and transition moments. ${ }^{17}$

The cis/trans photoisomerization can also be monitored with the help of transient absorption spectroscopy, where the $\mathrm{S}_{1}$ state is further excited to higher electronic states. Accordingly, we computed the transition energies and oscillator strengths from the active state of all trajectories to higher states up to about $4 \mathrm{eV}$ above the $\mathrm{S}_{1}$ in our QM/MM SHARC trajectories. Figure 8 shows the obtained time-resolved absorption spectra in DMSO.

Within 1 ps, the two initial absorption bands at 720 and $550 \mathrm{~nm}$ (blue line) blue-shift to 575 and $490 \mathrm{~nm}$ (light pink line), respectively (Figure 8B). After 250 fs (dark purple line), decay is observed in both absorption bands at 720 and $550 \mathrm{~nm}$. However, the intensity of the absorption band at $550 \mathrm{~nm}$ increases in the first $150 \mathrm{fs}$ (light green line in Figure 8A). The increased intensity of the $550 \mathrm{~nm}$ band agrees well with the experimentally time-resolved emission and transient absorption spectra, ${ }^{17,27}$ where this band is assigned as a dark state. 


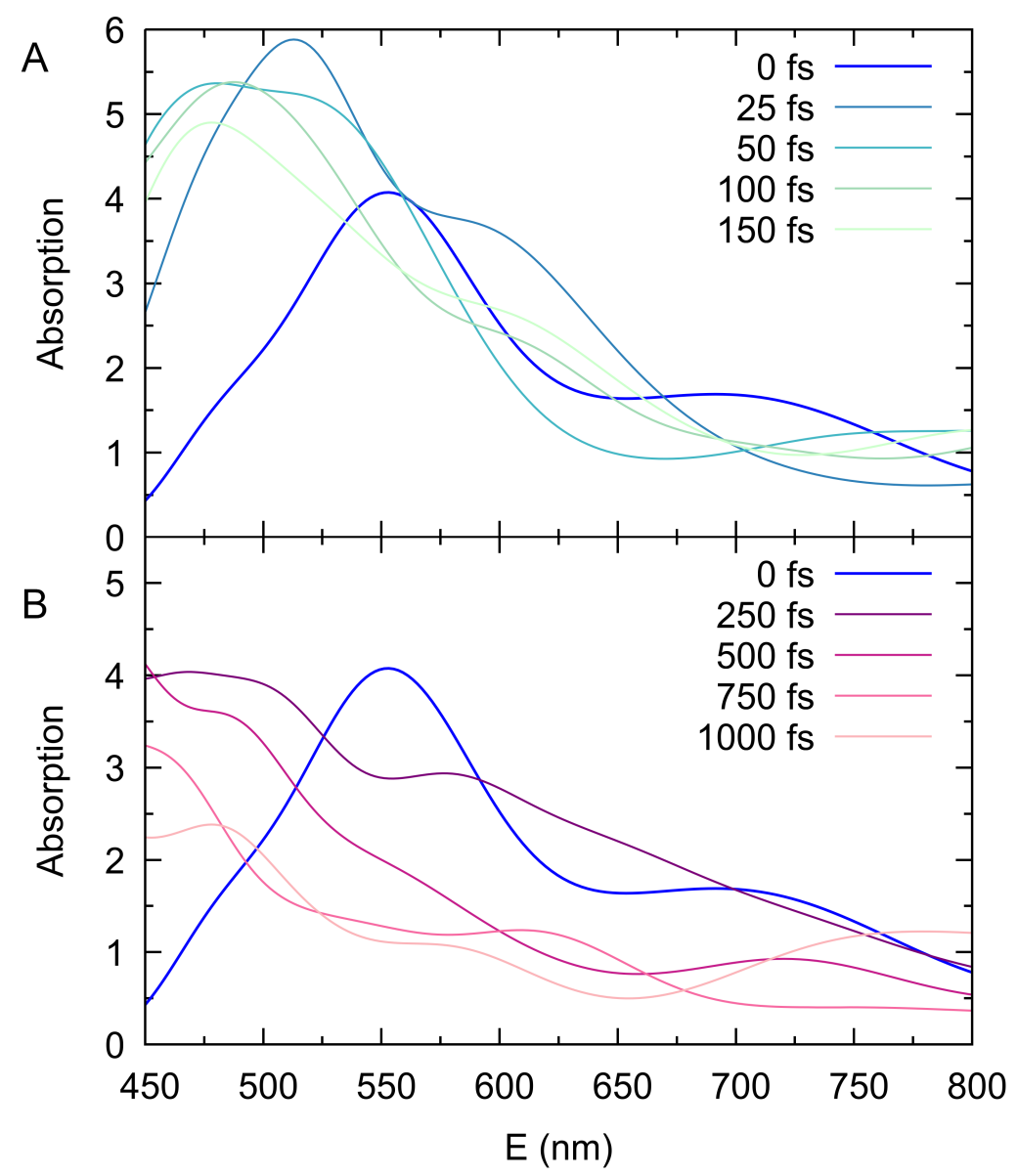

Figure 8: Simulated transient absorption spectra up to 1 ps: (A) 0-150 fs (0 fs in blue, 25-150 fs changes gradually from dark green to light green); (B) 250-1000 fs (0 fs in blue, 250-1000 fs changes gradually from dark purple to light pink). 
The experimental spectrum in cyclohexane ${ }^{27}$ shows two bands for the short-lived FrankCondon state (100 fs) at $760 \mathrm{~nm}$ and dark state $(1.6 \mathrm{ps})$ at $550 \mathrm{~nm}$, respectively, which were reminiscent of the two absorption bands found by our simulations. The Frank-Condon region at $720 \mathrm{~nm}(1.72 \mathrm{eV})$ is assigned as the cis-configuration, where the absorption intensity reduces after the excitation in our simulation. The energy gap between $\mathrm{S}_{1}$ and $\mathrm{S}_{n}(\mathrm{n}>1)$ states in the Frank-Condon region is about $1.72 \mathrm{eV}$ in the comparison with the energy gap of 2.25 $\mathrm{eV}(550 \mathrm{~nm})$ in the dark state, which is consistent with the experimental observations. ${ }^{27}$ The intensity of the absorption under $500 \mathrm{~nm}$ increases after $1 \mathrm{ps}$ in the experimental spectra, ${ }^{27}$ indicating that the trans-configuration is formed after 1 ps by isomerization in the molecular motor. From our simulated time-resolved absorption spectra, the absorption bands are assigned as trans (under $500 \mathrm{~nm}$ ), dark (500-720 nm), and Frank-Condon (720 nm) states.

Both time-resolved emission and absorption, identify the short-lived Frank-Condon state of the molecular motor in the first 150 fs, which is followed by a formation of a dark state, then the excited state relaxes to the ground state in about 1 ps.

\subsection{Solvation effects}

We shall first analyze solvation effect on the electronic ground state, using the trajectories generated from classical MD simulations. The distance distributions between all carbon atoms of $\mathbf{1}$ and sulfur/oxygen atoms in DMSO, noted as $\mathrm{r}_{\mathrm{C}-\mathrm{S}} / \mathrm{r}_{\mathrm{C}-\mathrm{O}}$, are analyzed statistically in Figure S7. These RDFs show that cis- and trans-configurations have similar solvation environments according to $g_{\mathrm{C}-\mathrm{S}}(\mathrm{r})$ and $g_{\mathrm{C}-\mathrm{O}}(\mathrm{r})$. To distinguish the six aromatic centers of $\mathbf{1}$, we further plot the distances between each of the ring centers and the solvents separately, shown as black lines in Figures 9 and S8, where six aromatic rings are labeled as a-f for the 1-cis configuration.

In Figure 9, the first peaks and valleys of $g_{\mathrm{C}-\mathrm{O}}(\mathrm{r})$ are at 5.6 and $7.2 \AA$ for the rings a, c, and $f$. The three aromatic rings have smaller steric hindrance, allowing DMSO to approach easier than to the other rings. The first peaks of $g_{\mathrm{C}-\mathrm{S}}(\mathrm{r})$ in rings a, c, and $\mathrm{f}$ (Fig. S8) are 


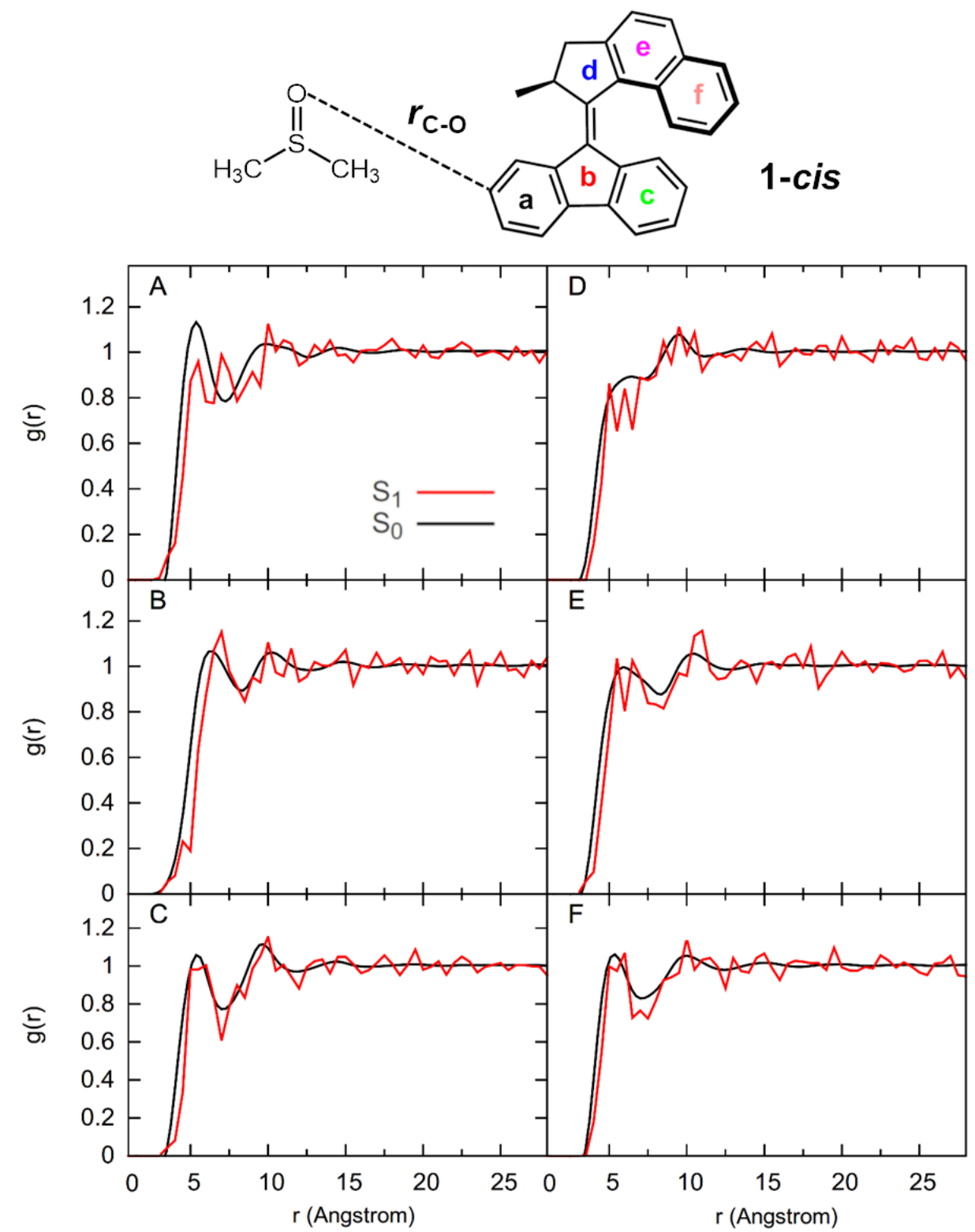

Figure 9: (A)-(F) RDFs of 1-cis, $g_{\mathrm{C}-\mathrm{O}}(\mathrm{r})$, in the ground (in black) and excited (in red) states for six aromatic rings a-f, respectively. 
similar to that of $g_{\mathrm{C}-\mathrm{O}}(\mathrm{r})$, indicating that the $\mathrm{S}=\mathrm{O}$ bonds in DMSO are parallel or slightly tilt to these rings due to the $\pi-\pi$ interactions. If the $\mathrm{S}=\mathrm{O}$ bonds were perpendicular to these rings, the difference between the first solvation shells of $\mathrm{S}$ and $\mathrm{O}$ atoms should be reflected in the bond length of $\mathrm{S}=\mathrm{O}$ bond, but this is not observed here.

We further investigate the orientation of $\mathrm{S}=\mathrm{O}$ bonds in the first solvation shell $(\mathrm{r}<8.0$ $\AA$ ) by analyzing the correlation between $g_{\mathrm{C}-\mathrm{S}}(\mathrm{r})$ and $g_{\mathrm{C}-\mathrm{O}}(\mathrm{r})$-illustrated in Fig. S9. It shows that the two-dimensional patterns in rings a, $\mathrm{c}$, and $\mathrm{f}$ are similar, close to the observation of the one-dimensional RDFs of 1-cis (Fig. 9 and S8). The RDFs $g_{\mathrm{C}-\mathrm{S}}(\mathrm{r})$ and $g_{\mathrm{C}-\mathrm{O}}(\mathrm{r})$ populate almost equally around the diagonals of the graphs, indicating that $\mathrm{S}=\mathrm{O}$ bonds are mostly parallel to the aromatic rings of the molecular motor.

The steric hindrance in ring $b$ is different to that in ring $d$, even if they are both fivemembered rings, leading to different first solvation shells. The first peaks of $g_{\mathrm{C}-\mathrm{O}}(\mathrm{r})$ and $g_{\mathrm{C}-\mathrm{S}}(\mathrm{r})$ of ring $\mathrm{b}$ are further than the other rings in Fig. 9 and S8, which is caused by the steric effect of ring b. For ring $\mathrm{d}, g_{\mathrm{C}-\mathrm{O}}(\mathrm{r})$ and $g_{\mathrm{C}-\mathrm{S}}(\mathrm{r})$ are similar to rings a, c, and d, but a smaller density is observed in the first solvation shell. On the other hand, the patterns of two-dimensional RDFs in Figure S9 are slightly different between $b$ and d rings within the first solvation shell. The higher population (dark red grid) occurs above the diagonal in ring $\mathrm{b}$, but under the diagonal in ring d. For ring b, the peaks of the population locate at 4.0 $\AA\left(\mathrm{r}_{\mathrm{C}-\mathrm{S}}\right)$ and $5.5 \AA\left(\mathrm{r}_{\mathrm{C}-\mathrm{O}}\right)$, indicating that $\mathrm{S}$ atoms point to the rings with smaller distance to the centers. Similarly, we could find that O atoms point to ring d from Figure S9D. The similar peaks in $g_{\mathrm{C}-\mathrm{O}}(\mathrm{r})$ and $g_{\mathrm{C}-\mathrm{S}}(\mathrm{r})$ (Fig. $9 \mathrm{E}$ and S8E) and population projection in their correlation (Fig. S9E) for ring e, likewise indicate that the $\mathrm{S}=\mathrm{O}$ bonds slightly tilt to ring e.

In Figure 10, we further evaluate the hydrogen bonds established by 1-cis and DMSO in the electronic ground state. The RDFs, $g_{\mathrm{H}-\mathrm{O}}(\mathrm{r})$ and $g_{\mathrm{H}-\mathrm{S}}(\mathrm{r})$, present distributions of the distances between all hydrogen atoms of the motor that can be connected to $\mathrm{O}$ and $\mathrm{S}$ atoms of DMSO. A similar analysis for 1-trans compared to 1-cis can be found in Fig. S10, as hydrogen bonding patterns are similar between cis and trans-configurations. The first peaks 
with lower population than 1.0 are at 2.9 and $4.7 \AA$ in $g_{\mathrm{H}-\mathrm{O}}(\mathrm{r})$ and $g_{\mathrm{H}-\mathrm{S}}(\mathrm{r})$, respectively, demonstrating the hydrogen bond between DMSO and the motor is very weak. However, the population of $g_{\mathrm{H}-\mathrm{S}}(\mathrm{r})$ (Figure 10B) is higher than that of $g_{\mathrm{H}-\mathrm{O}}(\mathrm{r})$ (Fig. 10A) because the hydrogen bond in $\mathrm{O}=\mathrm{S} \cdots \mathrm{H}$ is stronger than $\mathrm{S}=\mathrm{O} \cdots \mathrm{H}$. Taking RDFs $g_{\mathrm{C}-\mathrm{O}}(\mathrm{r})$ and $g_{\mathrm{C}-\mathrm{O}}(\mathrm{r})$ and orientation distribution also into account, the position and orientation of the solvent is mostly determined by the $\pi-\pi$ interaction between aromatic ring of the molecular motor, since the hydrogen bond is much weaker than the $\pi-\pi$ interactions.

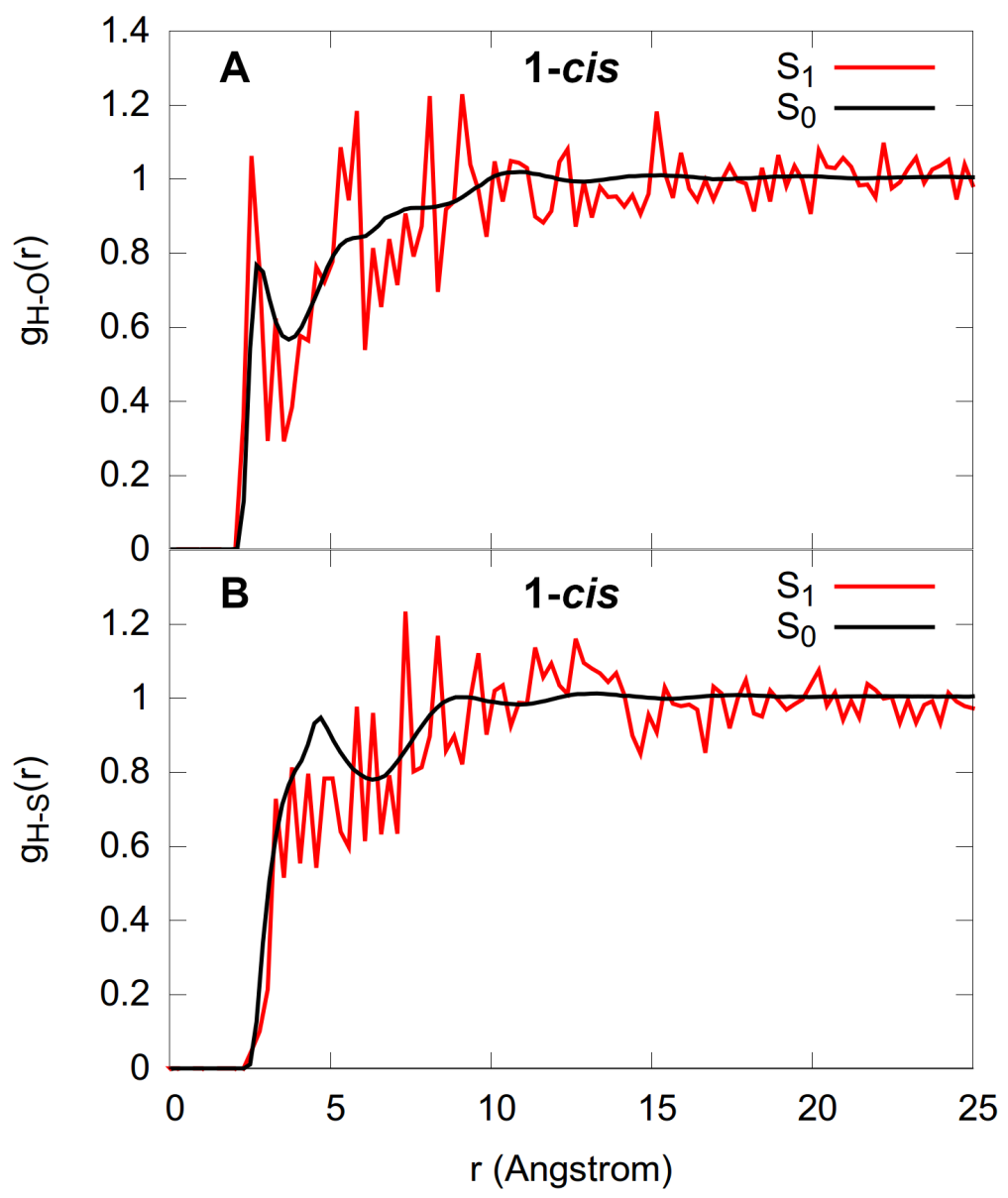

Figure 10: RDFs of 1-cis (A) $g_{\mathrm{H}-\mathrm{O}}(\mathrm{r})$ and $(\mathrm{B}) g_{\mathrm{H}-\mathrm{S}}(\mathrm{r})$ in the electronic ground (black) and excited (red) states.

We now proceed to shortly discuss the RDFs in the electronic excited state, as obtained from the QM/MM-SHARC simulations during 0.9-1.0 ps. To compare with the ground state, $g_{\mathrm{C}-\mathrm{O}}(\mathrm{r}), g_{\mathrm{C}-\mathrm{S}}(\mathrm{r})$, are plotted separately for six rings (red lines of Figures 9 , S8, and S11). 
The formation of hydrogen bonds in the excited state versus the ground state is presented in Figure 10. Due to the small number of trajectories, the RDFs in the $\mathrm{S}_{1}$ state are very noisy but it follows a parallel trend to the ground state, showing that the orientation of the solvents does not change during this time. Probably there is no charge redistribution in the molecular motor in the excited state, so the orientation of the solvents remains. We anticipate that the effect on the solvent orientation would be stronger in the excited state if the group - $\mathrm{R}$ of the molecular motor (recall Figure 1) is replaced by polar functional groups.

\subsection{Conclusion}

The excitation energies and potential energy surfaces of a molecular motor is investigated with TD-DFT, multiconfigurational, and $\mathrm{ADC}(2)$ approaches, in order to select a suitable method to run QM/MM excited state trajectories including the solvent DMSO. Based on computational cost and accuracy, $\mathrm{ADC}(2)$ is selected as a compromise. The QM/MMSHARC simulations of the photoisomerization process result in a quantum yield in DMSO of about $13 \%$ with a time constant of 0.98 ps. Due to the limitations of the single reference method $\mathrm{ADC}(2)$, this time constant obtained from a character-based representation is overestimated, while a time constant from the energy-based representation aligns with the experimental observation that the excited state decays to the ground state in about 1.5 ps.

Further, we simulate time-resolved emission and absorption spectra to find that the excited state of this molecule is trapped in the $\mathrm{S}_{1}$ dark state during $200 \mathrm{fs}$ before it decays to the ground state. The arrangement of the DMSO solvent is not affected after the excitation, as illustrated from comparing radial distribution function and orientation of DMSO between the ground and excited states. We expect larger changes in the orientation of the solvent in a molecular motor with higher polarity. Understanding the role of the solvent in the

photodynamics will be useful in designing novel molecular motors with high quantum yield and optimal isomerization process. 


\section{ORCID}

Jin Wen: 0000-0001-6136-8771

Sebastian Mai: 0000-0001-5327-8880

Leticia González: 0000-0001-5112-794X

\section{Acknowledgement}

We appreciate Professor Pedro A. Sánchez-Murcia for the helpful suggestions. J. W. thanks the Austrian Science Fund (FWF Project M 2709) for financial support. The authors gratefully acknowledge the continuous support of the University of Vienna and the Vienna Scientific Cluster (VSC) for generous allocation of computer resources.

\section{Supporting Information Available}

Optimized coordinates of different configurations in the ground and excited states. Relevant orbitals of the MS-CASPT2 and ADC(2) calculations. Additional analysis of SHARC simulations.

\section{References}

(1) Erbas-Cakmak, S.; Leigh, D. A.; McTernan, C. T.; Nussbaumer, A. L. Artificial Molecular Machines. Chem. Rev. 2015, 115, 10081-10206, DOI: 10.1021/acs.chemrev.5b00146.

(2) Feng, Y.; Ovalle, M.; Seale, J. S. W.; Lee, C. K.; Kim, D. J.; Astumian, R. D.; Stoddart, J. F. Molecular Pumps and Motors. J. Am. Chem. Soc. 2021, 143, 5569-5591, DOI: $10.1021 /$ jacs.0c13388.

(3) García-López, V.; Liu, D.; Tour, J. M. Light-Activated Organic Molecular Motors and Their Applications. Chem. Rev. 2020, 120, 79-124, DOI: 10.1021/acs.chemrev.9b00221. 
(4) Baroncini, M.; Silvi, S.; Credi, A. Photo- and Redox-Driven Artificial Molecular Motors. Chem. Rev. 2020, 120, 200-268, DOI: 10.1021/acs.chemrev.9b00291.

(5) Koumura, N.; Zijlstra, R. W. J.; van Delden, R. A.; Harada, N.; Feringa, B. L. Light-Driven Monodirectional Molecular Rotor. Nature 1999, 401, 152-155, DOI: $10.1038 / 43646$.

(6) Kassem, S.; Leeuwen, T. v.; Lubbe, A. S.; Wilson, M. R.; Feringa, B. L.; Leigh, D. A. Artificial Molecular Motors. Chem. Soc. Rev. 2017, 46, 2592-2621, DOI: 10.1039/C7CS00245A.

(7) Feringa, B. L. The Art of Building Small: From Molecular Switches to Motors (Nobel Lecture). Angew. Chem. Int. Ed. 2017, 56, 11060-11078, DOI: 10.1002/anie.201702979.

(8) Leeuwen, T. v.; Lubbe, A. S.; Štacko, P.; Wezenberg, S. J.; Feringa, B. L. Dynamic Control of Function by Light-Driven Molecular Motors. Nat. Rev. Chem. 2017, 1, 0096, DOI: $10.1038 / \mathrm{s} 41570-017-0096$.

(9) Vicario, J.; Meetsma, A.; Feringa, B. L. Controlling the Speed of Rotation in Molecular Motors. Dramatic Acceleration of the Rotary Motion by Structural Modification. Chem. Comm. 2005, 5910, DOI: 10.1039/b507264f.

(10) Browne, W. R.; Feringa, B. L. Making Molecular Machines Work. Nat. Nanotechnol. 2006, 1, 25-35, DOI: 10.1038/nnano.2006.45.

(11) Miller, R. J. D. Molecular Motor Speed Limits. Nat. Chem. 2012, 4, 523-525, DOI: 10.1038/nchem.1393.

(12) Roke, D.; Wezenberg, S. J.; Feringa, B. L. Molecular Rotary Motors: Unidirectional Motion around Double Bonds. Proc. Natl. Acad. Sci. U.S.A. 2018, 115, 9423-9431, DOI: $10.1073 /$ PNAS.1712784115. 
(13) Pfeifer, L.; Scherübl, M.; Fellert, M.; Danowski, W.; Cheng, J.; Pol, J.; Feringa, B. L. Photoefficient $2^{\text {nd }}$ Generation Molecular Motors Responsive to Visible Light. Chem. Sci. 2019, 10, 8768-8773, DOI: 10.1039/C9SC02150G.

(14) Sardjan, A. S.; Roy, P.; Danowski, W.; Bressan, G.; Nunes dos Santos Comprido, L.; Browne, W. R.; Feringa, B. L.; Meech, S. R. Ultrafast Excited State Dynamics in a First Generation Photomolecular Motor. ChemPhysChem 2020, 21, 594-599, DOI: 10.1002/cphc.201901179.

(15) Danowski, W.; van Leeuwen, T.; Abdolahzadeh, S.; Roke, D.; Browne, W. R.; Wezenberg, S. J.; Feringa, B. L. Unidirectional Rotary Motion in a Metal-Organic Framework. Nat. Nanotechnol. 2019, 14, 488-494, DOI: 10.1038/s41565-019-0401-6.

(16) Stolz, S.; Gröning, O.; Prinz, J.; Brune, H.; Widmer, R. Molecular Motor crossing the Frontier of Classical to Quantum Tunneling Motion. Proc. Natl. Acad. Sci. U.S.A. 2020, DOI: 10.1073/pnas.1918654117.

(17) Conyard, J.; Addison, K.; Heisler, I. A.; Cnossen, A.; Browne, W. R.; Feringa, B. L.; Meech, S. R. Ultrafast Dynamics in the Power Stroke of a Molecular Rotary Motor. Nat. Chem. 2012, 4, 547-551, DOI: 10.1038/nchem.1343.

(18) Wiley, T. E.; Konar, A.; Miller, N. A.; Spears, K. G.; Sension, R. J. Primed for Efficient Motion: Ultrafast Excited State Dynamics and Optical Manipulation of a Four Stage Rotary Molecular Motor. J. Phys. Chem. A 2018, 122, 7548-7558, DOI: 10.1021/acs.jpca.8b06472.

(19) Klok, M.; Janssen, L. P.; Browne, W. R.; Feringa, B. L. The Influence of Viscosity on the Functioning of Molecular Motors. Faraday Discuss. 2009, 143, 319-334, DOI: 10.1039/b901841g.

(20) Lubbe, A. S.; Böhmer, C.; Tosi, F.; Szymanski, W.; Feringa, B. L. Molecular 
Motors in Aqueous Environment. J. Org. Chem. 2018, 83, 11008-11018, DOI: 10.1021/acs.joc.8b01627.

(21) Beekmeyer, R.; Parkes, M. A.; Ridgwell, L.; Riley, J.; Chen, J.; Feringa, B. L.; Kerridge, A.; Fielding, H. H. Unravelling the Electronic Structure and Dynamics of an Isolated Molecular Rotary Motor in the Gas-Phase. Chem. Sci. 2017, 8, 6141-6148, DOI: 10.1039/C7SC01997A.

(22) Kazaryan, A.; Lan, Z.; Schäfer, L. V.; Thiel, W.; Filatov, M. Surface Hopping Excited-State Dynamics Study of the Photoisomerization of a Light-Driven Fluorene Molecular Rotary Motor. J. Chem. Theory Comput. 2011, 7, 2189-2199, DOI: $10.1021 / \operatorname{ct} 200199 w$.

(23) Pang, X.; Cui, X.; Hu, D.; Jiang, C.; Zhao, D.; Lan, Z.; Li, F. "Watching" the Dark State in Ultrafast Nonadiabatic Photoisomerization Process of a LightDriven Molecular Rotary Motor. J. Phys. Chem. A 2017, 121, 1240-1249, DOI: $10.1021 /$ acs.jpca.6b12253.

(24) Wezenberg, S. J.; Feringa, B. L. Supramolecularly Directed Rotary Motion in a Photoresponsive Receptor. Nat. Commun. 2018, 9, 1984, DOI: 10.1038/s41467-018-04249-x.

(25) Mai, S.; Richter, M.; Heindl, M.; Menger, M. F. S. J.; Atkins, A.; Ruckenbauer, M.; Plasser, F.; Ibele, L. M.; Kropf, S.; Oppel, M.; Marquetand, P.; González, L. SHARC2.1: Surface Hopping Including Arbitrary Couplings-Program Package for Non-Adiabatic Dynamics. sharc-md.org, 2019.

(26) Mai, S.; Marquetand, P.; González, L. Nonadiabatic Dynamics: The SHARC Approach. WIREs Comput. Mol. Sci. 2018, 8, e1370, DOI: 10.1002/wcms.1370.

(27) Hall, C. R.; Conyard, J.; Heisler, I. A.; Jones, G.; Frost, J.; Browne, W. R.; Feringa, B. L.; Meech, S. R. Ultrafast Dynamics in Light-Driven Molecular Rotary 
Motors Probed by Femtosecond Stimulated Raman Spectroscopy. J. Am. Chem. Soc. 2017, 139, 7408-7414, DOI: 10.1021/jacs.7b03599.

(28) Levine, B. G.; Coe, J. D.; Martínez, T. J. Optimizing Conical Intersections without Derivative Coupling Vectors: Application to Multistate Multireference Second-Order Perturbation Theory (MS-CASPT2). J. Phys. Chem. B 2008, 112, 405-413., DOI: $10.1021 / j p 0761618$.

(29) Li Manni, G.; Carlson, R. K.; Luo, S.; Ma, D.; Olsen, J.; Truhlar, D. G.; Gagliardi, L. Multiconfiguration Pair-Density Functional Theory. J. Chem. Theory Comput. 2014, 10, 3669-3680, DOI: 10.1021/ct500483t.

(30) Carlson, R. K.; Li Manni, G.; Sonnenberger, A. L.; Truhlar, D. G.; Gagliardi, L. Multiconfiguration Pair-Density Functional Theory: Barrier Heights and Main Group and Transition Metal Energetics. J. Chem. Theory Comput. 2015, 11, 82-90, DOI: $10.1021 / \operatorname{ct} 5008235$.

(31) Hättig, C. In Response Theory and Molecular Properties (A Tribute to Jan Linderberg and Poul Jørgensen); Jensen, H., Ed.; Advances in Quantum Chemistry; Academic Press, 2005; Vol. 50; pp 37-60, DOI: 10.1016/S0065-3276(05)50003-0.

(32) Casida, M. E. In Recent Developments and Applications of Modern Density Functional Theory; Seminario, J., Ed.; Theoretical and Computational Chemistry; Elsevier, 1996; Vol. 4; pp 391-439, DOI: 10.1016/S1380-7323(96)80093-8.

(33) Zobel, J. P.; Nogueira, J. J.; González, L. The IPEA dilemma in CASPT2. Chem. Sci. 2017, 8, 1482-1499, DOI: 10.1039/C6SC03759C.

(34) Li Manni, G.; Carlson, R. K.; Luo, S.; Ma, D.; Olsen, J.; Truhlar, D. G.; Gagliardi, L. Multiconfiguration Pair-Density Functional Theory. J. Chem. Theory Comput. 2014, 10, 3669-3680, DOI: 10.1021/ct500483t. 
(35) Dunning, T. H. Gaussian Basis Sets for Use in Correlated Molecular Calculations. I. The Atoms Boron Through Neon and Hydrogen. J. Chem. Phys. 1989, 90, 1007-1023, DOI: $10.1063 / 1.456153$.

(36) Fdez. Galván, I.; Vacher, M.; Alavi, A.; Angeli, C.; Aquilante, F.; Autschbach, J.; Bao, J. J.; Bokarev, S. I.; Bogdanov, N. A.; Carlson, R. K.; Chibotaru, L. F.; Creutzberg, J.; Dattani, N.; Delcey, M. G.; Dong, S. S.; Dreuw, A.; Freitag, L.; Frutos, L. M.; Gagliardi, L.; Gendron, F.; Giussani, A.; González, L.; Grell, G.; Guo, M.; Hoyer, C. E.; Johansson, M.; Keller, S.; Knecht, S.; Kovačević, G.; Källman, E.; Li Manni, G.; Lundberg, M.; Ma, Y.; Mai, S.; Malhado, J. P.; Malmqvist, P. Å.; Marquetand, P.; Mewes, S. A.; Norell, J.; Olivucci, M.; Oppel, M.; Phung, Q. M.; Pierloot, K.; Plasser, F.; Reiher, M.; Sand, A. M.; Schapiro, I.; Sharma, P.; Stein, C. J.; Sørensen, L. K.; Truhlar, D. G.; Ugandi, M.; Ungur, L.; Valentini, A.; Vancoillie, S.; Veryazov, V.; Weser, O.; Wesołowski, T. A.; Widmark, P.-O.; Wouters, S.; Zech, A.; Zobel, J. P.; Lindh, R. OpenMolcas: From Source Code to Insight. J. Chem. Theory Comput. 2019, 15, 5925-5964, DOI: 10.1021/acs.jctc.9b00532.

(37) TURBOMOLE V7.1 2016, a development of University of Karlsruhe and Forschungszentrum Karlsruhe GmbH, 1989-2007, TURBOMOLE GmbH, since 2007; available from http://www.turbomole.com.

(38) Frisch, M. J.; Trucks, G. W.; Schlegel, H. B.; Scuseria, G. E.; Robb, M. A.; Cheeseman, J. R.; Scalmani, G.; Barone, V.; Petersson, G. A.; Nakatsuji, H.; Li, X.; Caricato, M.; Marenich, A. V.; Bloino, J.; Janesko, B. G.; Gomperts, R.; Mennucci, B.; Hratchian, H. P.; Ortiz, J. V.; Izmaylov, A. F.; Sonnenberg, J. L.; WilliamsYoung, D.; Ding, F.; Lipparini, F.; Egidi, F.; Goings, J.; Peng, B.; Petrone, A.; Henderson, T.; Ranasinghe, D.; Zakrzewski, V. G.; Gao, J.; Rega, N.; Zheng, G.; Liang, W.; Hada, M.; Ehara, M.; Toyota, K.; Fukuda, R.; Hasegawa, J.; Ishida, M.; Nakajima, T.; Honda, Y.; Kitao, O.; Nakai, H.; Vreven, T.; Throssell, K.; Montgomery, J. A., Jr.; 
Peralta, J. E.; Ogliaro, F.; Bearpark, M. J.; Heyd, J. J.; Brothers, E. N.; Kudin, K. N.; Staroverov, V. N.; Keith, T. A.; Kobayashi, R.; Normand, J.; Raghavachari, K.; Rendell, A. P.; Burant, J. C.; Iyengar, S. S.; Tomasi, J.; Cossi, M.; Millam, J. M.; Klene, M.; Adamo, C.; Cammi, R.; Ochterski, J. W.; Martin, R. L.; Morokuma, K.; Farkas, O.; Foresman, J. B.; Fox, D. J. Gaussian 16 Revision A.03. 2016; Gaussian Inc. Wallingford CT.

(39) Wang, B.; Merz, K. M. A fast QM/MM (Quantum Mechanical/Molecular Mechanical) Approach to Calculate Nuclear Magnetic Resonance Chemical Shifts for Macromolecules. J. Chem. Theory Comput. 2006, 2, 209-215, DOI: 10.1021/ct050212s.

(40) Fox, T.; Kollman, P. A. Application of the RESP Methodology in the Parametrization of Organic Solvents. J. Phys. Chem. B 1998, 102, 8070-8079, DOI: 10.1021/jp9717655.

(41) Case, D.; Ben-Shalom, I.; Brozell, S.; Cerutti, D.; Cheatham, T.; III,; Cruzeiro, V.; Darden, T.; Duke, R.; Ghoreishi, D.; Gilson, M.; Gohlke, H.; Goetz, A.; Greene, D.; Harris, R.; Homeyer, N.; Huang, Y.; Izadi, S.; Kovalenko, A.; Kurtzman, T.; Lee, T.; LeGrand, S.; Li, P.; Lin, C.; Liu, J.; Luchko, T.; Luo, R.; Mermelstein, D.; Merz, K.; Miao, Y.; Monard, G.; Nguyen, C.; Nguyen, H.; Omelyan, I.; Onufriev, A.; Pan, F.; Qi, R.; Roe, D.; Roitberg, A.; Sagui, C.; Schott-Verdugo, S.; Shen, J.; Simmerling, C.; Smith, J.; SalomonFerrer, R.; Swails, J.; Walker, R.; Wang, J.; Wei, H.; Wolf, R.; Wu, X.; Xiao, L.; York, D.; (2018), P. K. AMBER 2018. University of California, San Francisco.

(42) Plasser, F.; Ruckenbauer, M.; Mai, S.; Oppel, M.; Marquetand, P.; González, L. Efficient and Flexible Computation of Many-Electron Wave Function Overlaps. J. Chem. Theory Comput. 2016, 12, 1207-1219, DOI: 10.1021/acs.jctc.5b01148.

(43) Granucci, G.; Persico, M.; Toniolo, A. Direct semiclassical simulation of photochemical 
processes with semiempirical wave functions. J. Chem. Phys. 2001, 114, 10608-10615, DOI: $10.1063 / 1.1376633$.

(44) Granucci, G.; Persico, M.; Zoccante, A. Including Quantum Decoherence in Surface Hopping. J. Chem. Phys. 2010, 133, DOI: 10.1063/1.3489004.

(45) Ponder, J. W. Tinker Molecular Modeling. https://dasher.wustl.edu/tinker/ (accessed July 23, 2018).

(46) Richter, M.; Marquetand, P.; González-Vázquez, J.; Sola, I.; González, L. SHARC: ab initio Molecular Dynamics with Surface Hopping in the Adiabatic Representation Including Arbitrary Couplings. J. Chem. Theory Comput. 2011, 7, 1253-1258, DOI: $10.1021 /$ ct1007394.

(47) Neese, F. Software update: the ORCA program system, version 4.0. WIREs Comput. Mol. Sci. 2018, 8, e1327, DOI: 10.1002/wcms.1327.

(48) Bhadra, M.; Kandambeth, S.; Sahoo, M. K.; Addicoat, M.; Balaraman, E.; Banerjee, R. Triazine Functionalized Porous Covalent Organic Framework for Photo-organocatalytic E-Z Isomerization of Olefins. J. Am. Chem. Soc. 2019, 141, 6152-6156, DOI: 10.1021/jacs.9b01891.

(49) Gómez, S.; Ibele, L. M.; González, L. The 3s Rydberg State as a Doorway State in the Ultrafast Dynamics of 1,1-Difluoroethylene. Phys. Chem. Chem. Phys. 2019, 21, 4871-4878, DOI: 10.1039/C8CP07766E.

(50) Boggio-Pasqua, M.; Bearpark, M. J.; Robb, M. A. Toward a Mechanistic Understanding of the Photochromism of Dimethyldihydropyrenes. J. Org. Chem. 2007, 72, 4497-4503, DOI: $10.1021 /$ jo070452v.

(51) Conyard, J.; Stacko, P.; Chen, J.; McDonagh, S.; Hall, C. R.; Laptenok, S. P.; Browne, W. R.; Feringa, B. L.; Meech, S. R. Ultrafast Excited State Dynamics in 
Molecular Motors: Coupling of Motor Length to Medium Viscosity. J. Phys. Chem. A 2017, 121, 2138-2150, DOI: 10.1021/acs.jpca.7b00087.

(52) Parker, S. M.; Roy, S.; Furche, F. Multistate Hybrid Time-Dependent Density Functional Theory with Surface Hopping Accurately Captures Ultrafast Thymine Photodeactivation. Phys. Chem. Chem. Phys. 2019, 21, 18999-19010, DOI: $10.1039 / \mathrm{c} 9 \mathrm{cp} 03127 \mathrm{~h}$. 


\section{Graphical TOC Entry}

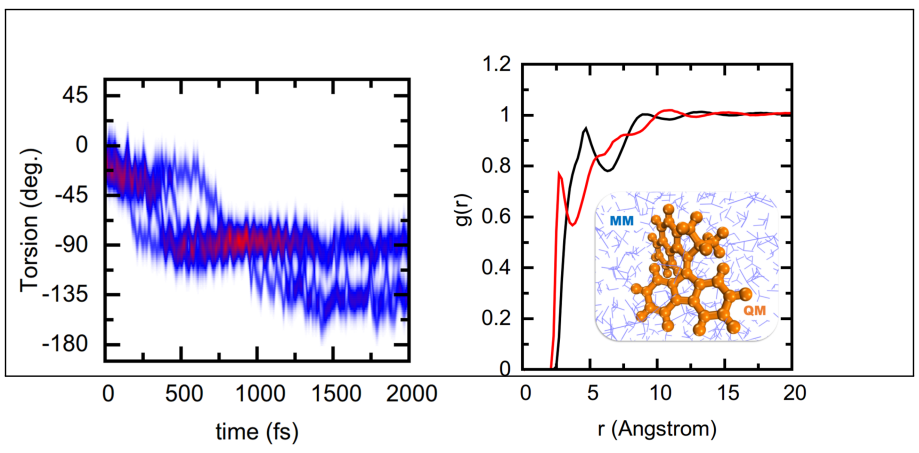

